\title{
O Ensino do Conceito Geográfico de Paisagem por meio da Literatura de Cordel a partir de uma Oficina Pedagógica
}

\author{
The Geographic Concept Landscape Teaching through the String Literature form a \\ Pedagogical Workshop
}

\section{La Enseñanza del Concepto Geográfico del Paisaje a través de la Literatura de Cordel a partir de un Taller Pedagógico}

\author{
Patrícia Honório Moura da Silva ${ }^{1}$ \\ Ricardo Lopes Fonseca
}

\begin{abstract}
RESUMO: O presente relato de experiência, realizado a partir de uma oficina pedagógica, aborda a possibilidade de se utilizar interdisciplinarmente a literatura e a Geografia no que tange ao ensino do conceito de paisagem, buscando assim uma maior integração entre diferentes disciplinas e a aproximação dos conteúdos trabalhados em sala de aula com a realidade dos alunos. Neste sentido, o principal objetivo dessa oficina pedagógica foi o de identificar as reais contribuições do uso da literatura no ensino do conceito geográfico de paisagem. Para tanto, num primeiro momento é feita a discussão acerca da interdisciplinaridade e as possibilidades frente à Geografia. Por fim trabalha-se o conceito de paisagem a partir dos cordéis. Além disso, tem-se o relato da oficina "paisagens nos cordéis" e a análise dos materiais produzidos pelos alunos na mesma. A partir da atividade aplicada e da análise dos cordéis produzidos, foi possível perceber que a literatura possibilita aos alunos uma maior aproximação dos conteúdos trabalhados com o seu cotidiano e que o mesmo permite uma análise da paisagem que vai além do visível, pois exige um olhar mais crítico sobre os diferentes cenários abordados nesta forma de literatura.
\end{abstract}

PALAVRAS-CHAVE: Ensino. Paisagem. Interdisciplinaridade.

ABSTRACT: This present experience report, carried out from a pedagogical workshop, discusses the possibility of using interdisciplinary y literature and geography in relation $n$ to the tea ching of the landscape concept, thus seeking a greater reintegration between different disciplines and the approximation $n$ of the contents worked in the classroom with the reality of the students. In this sense, the main objective of the pedagogical workshop was to identify the real contribution soft the use of literature in teaching the geographical concept landscape. To do so, the discussion about interdisciplinary and the possibilities of geography is discussed. Finally the concept to fland scapeis worked out from the cords. In addition, the reis the report of the workshop "landscapes in the cords" and the analysis of the materials produced by the students in it. From the applied activity and analysis of the produced cords, it was possible to perceive that the literature allows the students a greater

\footnotetext{
${ }^{1}$ Universidade Estadual de Londrina, Campus Universitário. CEP: 86.051-990, Londrina - Paraná. Caixa Postal: 6001, Londrina - Paraná, patriciahonorio014@gmail.com.

2 Departamento de Geociências da Universidade Estadual de Londrina. Campus Universitário. CEP: 86.051-990, Londrina - Paraná. Caixa Postal: 6001, ricardolopesfonseca@hotmail.com.
} 
approximation of the contents worked with their daily life and that it allows ananalys is of the land scape that goes beyond the visible, since it requires a look More critical about the different scenarios addressed in this form of literature.

KEYWORDS: Teaching. Landscape. Interdisciplinarity.

RESUMEN: El presente relato de experiencia, realizado a partir de un taller pedagógico, aborda la posibilidad de utilizar interdisciplinariamente la literatura y la geografía en lo que se refiere a la enseñanza del concepto de paisaje, buscando así una mayor integración entre diferentes disciplinas y la aproximación de los contenidos trabajados en el aula con la realidad de los alumnos. En ese sentido, el principal objetivo de este taller pedagógico fue identificar las reales contribuciones del uso de la literatura en la enseñanza del concepto geográfica del paisaje. Por lo tanto, en un primer momento se hace la discusión sobre la interdisciplinaridad y las posibilidades delante de la geografía. Por fin se trabaja el concepto de paisaje a partir de los cordeles. Además, se tiene el relato del taller "paisajes en los cordeles" y el análisis de los materiales producidos por los alumnos en el mismo. A partir de la actividad aplicada y del análisis de los cordeles producidos, se reveló que la literatura posibilita a los alumnos una mayor aproximación de los contenidos trabajados con su cotidiano y que el mismo permite un análisis del paisaje que va más allá de lo visible, pues exige una mirada más crítica sobre los diferentes escenarios abordados en esta forma de literatura.

PALABRAS CLAVES: Enseñanza. Paisaje. Interdisciplinariedad.

\section{INTRODUÇÃO}

O ensino de Geografia foi, durante muitos anos, pautado na descrição e memorização dos conteúdos cabíveis a esta disciplina. No entanto, atualmente, existe uma busca por mecanismos e metodologias que possibilitem um ensino mais humano e que permita a maior participação dos alunos, despertando assim o interesse dos mesmos. Ao se pensar o espaço geográfico, não é possível entendê-lo em sua totalidade utilizando-se apenas de ferramentas exclusivas da Geografia, neste sentido recursos como as músicas, a literatura e as fotografias possibilitam uma aproximação dos conteúdos da realidade dos alunos e facilitam a aprendizagem acerca do mesmo.

A literatura possibilita a valorização da subjetividade, tanto dos autores quanto de seus leitores. Além disso, quando se trata dos cordéis, por exemplo, é possível contemplar a descrição a respeito dos cotidianos e em muitos casos se tem denúncias referente às vivências precárias do ser humano. Deste modo, ao se trabalhar a Geografia em união com a literatura, abre-se um grande leque de discussões que podem ser feitas incentivando assim a criticidade do aluno. Portanto, é importante que se compreenda como esta abordagem interdisciplinar se dá e quais as vantagens da busca do rompimento das fronteiras disciplinares. 
Sendo assim, este texto tem como objetivo investigar as contribuições do uso da literatura de cordel no ensino do conceito geográfico de paisagem, tendo como procedimentos metodológicos a revisão de bibliografia pertinente ao tema e aplicação de uma oficina no colégio Willie Davids - Londrina - PR, no $2^{\circ}$ ano do ensino médio da rede pública.

Por fim, a partir da análise do material produzido na oficina, foi possível verificar a compreensão dos alunos a respeito da temática e a capacidade de enxergá-la no seu cotidiano. Além disso, durante a atividade, a interação e a participação dos alunos foi diferenciada, sendo estes construtores do próprio conhecimento, que mais tarde foi exemplificado em um cordel.

\section{GEOGRAFIA E LITERATURA: UMA PROPOSTA INTERDISCIPLINAR}

No decorrer da história da Geografia houve um longo período em que os debates epistemológicos foram evitados, pois se acreditava que esta ciência deveria se ocupar apenas dos aspectos visíveis das coisas, e seus métodos se baseavam na descrição do espaço geográfico, evitando assim grandes discussões ou debates acerca dos fenômenos ou a respeito do próprio objeto desta ciência. Isto se deu principalmente na chamada Geografia Tradicional, pois, segundo Moraes (2014), há atualmente um pluralismo de paradigmas na Geografia, ou seja, existem diferentes formas de se compreender a realidade, com ideias, explicações e normas também distintas. Essa diversidade permitiu a abertura de discussões e debates que enriquecem ainda mais a produção intelectual na Geografia. Apesar de serem distintos os olhares lançados na investigação do mundo real, de acordo com Gomes (2009), quando se trata da Geografia ainda é a espacialidade humana o tema central. Neste sentido, qualquer fenômeno passível de espacialização permite sua abordagem pela Geografia, estabelecendo um diálogo com a área do conhecimento que o investiga.

Pode-se afirmar que hoje a Geografia se encontra privilegiada na possibilidade de trabalhar conteúdos de forma interdisciplinar. Moraes (2014), afirma que como a Geografia é um campo que foi estabelecido antes da institucionalização da ciência moderna, ela se revela como um lócus favorecido para discutir os limites metodológicos interdisciplinares e propor uma transposição dos mesmos. Sendo assim, esta disciplina está inserida num paradoxo, pois não se situa em apenas um lugar dentro da divisão das ciências naturais e sociais (SUERTEGARAY, 2003).

Ainda de acordo com Suertegaray (2003), quando se toma o espaço geográfico como um conceito balizador da Geografia pode-se dizer que este propõe a conjunção do natural e do humano, sendo transformado na expressão da articulação entre a natureza e a 
sociedade. Desta forma, o espaço geográfico cria uma interface entre as ciências naturais e as ciências sociais, compreendendo, de acordo com a autora, "[...] um todo uno e múltiplo aberto a múltiplas conexões que se expressam por meio dos diferentes conceitos como paisagem, região, território" (SUERTEGARAY, 2003, p. 48).

Logo, o espaço geográfico pode ser abordado a partir dos conceitos de paisagem, território, região, lugar ou ambiente, sem se desconsiderar que cada uma dessas dimensões está contida em todas as demais (SUERTEGARAY, 2003). Quando se busca entender o espaço por sua totalidade há a necessidade de se buscar a diversidade e de abrir-se a outras formas de se ver e expressar esse espaço, tentando romper com o olhar desfragmentado e descontextualizado do mundo (TEIXEIRA; FREDERICO, 2009). Neste sentido, a literatura se torna uma aliada ao ensino, pois contempla as diversas dimensões contidas no espaço geográfico (econômica, política, cultural, demográfica e ambiental, por exemplo), levando em conta as interpretações de seu emissor e dos receptores.

A partir da leitura interna da Geografia é que se pode perceber a multidisciplinariedade dos temas e problemas estudados por esta disciplina. Deste modo, há certa facilidade em transitar por diferentes campos e abordagens (SUERTEGARAY, 2003), sendo possível fazer aproximações, principalmente no campo do ensino, com disciplinas como a História, a Literatura, a Língua Portuguesa e a Sociologia, por exemplo (TEIXEIRA; FREDERICO, 2009).

Em busca do rompimento com a fragmentação da ciência trazida pelo positivismo e reforçada pela ciência moderna, tem-se a partir da década de 1960 o início dos estudos a respeito da interdisciplinaridade. Esta surgiu a fim de recuperar o diálogo entre as diversas áreas do conhecimento e em busca de um sentido mais humano para a educação (FAZENDA, 2006). A interdisciplinaridade é muitas vezes compreendida como o mero cruzamento de disciplinas ou de parte dos conteúdos que eventualmente podem fornecer contato nas atividades cotidianas da escola. Esta visão, no entanto, não reconhece a necessidade constante das práticas interdisciplinares nas atividades letivas e que todo 0 corpo escolar deve se envolver, não limitando apenas a conteúdos e disciplinas com afinidades (TEIXEIRA; FREDERICO, 2009).

Um ensino interdisciplinar pode oferecer perspectivas positivas na vida do aluno melhorando assim a compreensão dos conteúdos e refletindo no cotidiano do mesmo. No que se refere ao ensino da Geografia, pode-se afirmar que este passou por diversas mudanças no decorrer dos anos. De acordo com Carvalho (2007), durante o período da chamada Geografia tradicional esta disciplina passou a ser vista como uma matéria decorativa, e seu ensino se baseava na memorização de nomes de rios, montanhas e outros aspectos do espaço geográfico. O espaço era apenas descrito, sem análises. As 
aulas eram expositivas e se veiculavam conteúdos como se fossem verdades absolutas, sendo o professor o detentor do conhecimento e o aluno o receptor. Muitas vezes tal matéria servia para a consolidação do sentimento de nacionalismo entre os alunos. Houve diversas falhas desses métodos de ensino, como a desmotivação do aluno, que era visto como uma "tábula rasa" sem nenhum conhecimento a priori, além da formação de sujeitos que não analisavam e interpretavam o meio em que estavam inseridos.

Ainda de acordo com Carvalho (2007), a sociedade está vivenciando outros tempos e muitas mudanças já ocorreram como a evolução das tecnologias e a rapidez com que se tem acesso a diferentes informações em diferentes locais. Neste sentido, devido as contradições internas e as críticas à Geografia Tradicional, esta se viu praticamente superada. Ao mesmo tempo tem-se o surgimento da modernidade, um novo paradigma. Segundo a autora, o que era tido como novo atualmente já não suporta as mudanças existentes e se vê envelhecido. Sendo assim, a crise na Geografia vem acompanhada da crise no ensino, da crise da própria ciência e na crise da modernidade.

A introdução deste novo paradigma civilizatório não significa, segundo a autora, a total substituição do anterior, mas as mudanças são evidentes. Vivemos em um mundo mais técnico e multissensorial, ou seja, todos os sentidos passam a ter importância, além também da valorização do subjetivo. É neste cenário de crises e mudanças que novos desafios surgem em sala de aula, principalmente no trato com a Geografia.

Os alunos se deparam com espacialidades que vão além da horizontalidade dos fenômenos e de sua distribuição. Deve-se levar em conta que a trama que marca os espaços é resultado da trama da vida das pessoas, sendo assim os objetos estudados neste espaço não são externos à vida dos alunos. Para se levar em conta esta subjetividade é preciso considerar o imaginário, pois este dá sentido aos objetos geográficos existentes, dando significados que vão além daquilo que é visível. Um dos meios de se valorizar e expressar estes significados é a literatura, que:

[...] dá forma concreta a sentimentos, dilemas criados pela imaginação, ou seja, o poder imagético tem papel fundamental, pois tornam reais os sonhos, as angústias. Ao efetivar-se em texto, a Literatura dá, portanto a imaginação a roupagem das palavras para interligar tempos e espaços, autores e leitores em um gesto de comunicação solidária. (MORAES; CALLAI, 2012, p. 7).

Encontra-se na literatura um meio para uma abordagem mais abrangente do espaço, pois a mesma retrata diferentes tempos, modos de vida e pensamentos, todos refletidos e sendo reflexo do lugar em que estão inseridos. 


\section{O CONCEITO DE PAISAGEM NOS CORDÉIS}

O ensino, para Cavalcanti (1998), em geral, objetiva a aprendizagem ativa dos alunos e busca o desenvolvimento de capacidades cognitivas e operativas, por meio da formação de conceitos. Assim, todas as ciências requerem o domínio de conceitos específicos e de uma linguagem própria. Nessa lógica, a Geografia possui um corpo conceitual e, consequentemente, uma linguagem, que se tornaram fundamentais para a análise dos fenômenos geográficos, neste sentido:

[...] a geografia tem como objeto de estudo a sociedade que, no entanto, é objetivada via cinco conceitos-chave que guardam entre si forte grau de parentesco, pois todos se referem à ação humana modelando a superfície terrestre: paisagem, região, espaço, lugar e território (CORRÊA, 2007, p. 16).

Tais conceitos não são exclusivos da ciência geográfica, sendo amplamente discutidos por outras ciências e pelo senso comum. No centro do debate cada conceito possui várias compreensões, ancoradas em determinadas correntes do pensamento, com ênfase para as correntes do pensamento geográfico: Geografia Tradicional, Geografia Crítica, Geografia Humanista e Geografia da Percepção.

Nesse sentido, as discussões acerca dos conceitos geográficos devem ser feitas conforme uma perspectiva holística. Ou seja, o saber científico e o saber cotidiano devem entrecruzar-se e integrar-se. Assim como as acepções de cada corrente epistemológica devem ser consideradas, uma vez que todas possuem sua contribuição em aspectos específicos. A fim de retomar as diferentes visões e concepções a respeito do conceito abordado nesta oficina pedagógica, é necessária a realização de um panorama das diversas abordagens do conceito nas diferentes correntes geográficas.

O conceito de paisagem, tida como enfoque desta oficina pedagógica, foi bastante evidenciado na Geografia Tradicional, sendo considerada como o próprio objeto da ciência geográfica. Para essa corrente, paisagem era considerada a melhor expressão do relacionamento entre o homem e o meio (CAVALCANTI, 1998).

Já na Nova Geografia, ou Geografia Teorética-Quantitativa, a noção de paisagem foi substituída pela noção de sistema espacial ou organização espacial (CAVALCANTI, 1998). Tal mudança pode ser compreendida devido à função atribuída a essa Geografia, uma Geografia voltada ao planejamento, ao Estado.

Para a Geografia Crítica, o conceito de paisagem pode ser definindo como tudo o que a visão humana alcança, sendo formada não apenas de volumes, mas também de movimento, sons, odores etc. Neste sentido, pode-se afirmar que a paisagem possui uma 
dimensão da percepção, ou seja, ela depende dos sentidos. Quando se trata da percepção o autor afirma que somente ela não basta para caracterizar o conhecimento referente a determinada paisagem, tendo em vista que essa percepção se dá de forma viciada e seletiva. Daí surge o desafio de ultrapassar os aspectos corpóreos da paisagem e se chegar ao seu significado (SANTOS, 2008).

Ainda de acordo com Santos (2008) paisagem é reflexo da vida social, sendo assim ela está diretamente relacionada com a produção do espaço geográfico, pois cada forma de se produzir exige do espaço diferentes organizações que irão culminar em paisagens distintas. E esses processos são históricos, estão inseridos em um período específico, desta forma a paisagem se torna um conjunto de objetos sobrepostos, todos com diferentes idades. Portanto, a paisagem não é estática, sempre será um objeto de mudanças.

$\mathrm{Na}$ visão da Geografia da Percepção, a paisagem é uma composição mental resultante de uma seleção e estruturação subjetiva a partir de informações emitidas pelo meio. Essas se tornam compreensíveis aos homens e orientam seus comportamentos. Em suma, para essa perspectiva, a paisagem é um conjunto de signos estruturado segundo o próprio sujeito (CAVALCANTI, 1998).

Todas as diferentes concepções fornecem contribuições ao estudo da paisagem, porém no presente texto a seleção da perspectiva crítica no trato com o conceito se deveu ao fato de que nesta concepção os sentidos são extremamente importantes para a construção do conceito. A paisagem, segundo Cavalcanti (1998), revela o imaginário social, valores, crenças e os sentimentos dos que a constroem. Além disso, nesta perspectiva há a possibilidade de se trabalhar as intencionalidades que envolvem as paisagens, pois as mesmas são consideradas reflexos de uma sociedade. Sendo assim, estas expressam os interesses e necessidades de um determinado momento.

Quando é levado em conta que a paisagem é uma expressão da sociedade e de seu modo de produzir e de se relacionar, os cordéis tornam-se, portanto, aliados no processo de ensino de tal conceito. Este tipo de literatura, de acordo com Curran (1991), tem sua origem em Portugal e faz parte dos acervos literários do Brasil desde o século XVI, trazida pelos colonizadores. No entanto, é principalmente a partir do século XIX que estes ganham expressividade como produção literária nordestina. Vale ressaltar que os cordéis eram um meio em que se faziam denúncias e se escrevia acerca do cotidiano dos autores. Neste sentido, as descrições e análises de paisagens são muito ricas nos mesmos.

Ainda conforme Curran (1991), os "livrinhos" eram inicialmente escritos em prosa e mais tarde foram transformados em poesias. A escrita era popular, não havendo a necessidade de formações acadêmicas ou de muito estudo para escrevê-los. Deste modo, os cordéis são ricos nas descrições e análises que os próprios escritores faziam referentes aos acontecimentos e as paisagens que os cercavam. 


\section{PROCEDIMENTOS METODOLÓGICOS}

Para trabalhar de forma prática o uso dos cordéis como ferramenta de ensino do conceito de paisagem foi aplicada uma oficina no Colégio Estadual Dr. Willie Davids, localizado na zona central de Londrina. A turma participante foi a do $2^{\circ}$ ano do ensino médio, do período da manhã, contando com 17 alunos em sala de aula.

A oficina foi iniciada com questionamentos a respeito do conhecimento dos alunos acerca dos cordéis. Alguns alunos se manifestaram e mostraram já ter tido contado com a literatura, compreendendo a sua construção popular e principalmente a origem nordestina. Em seguida alguns cordéis foram distribuídos para que os alunos observassem as poesias e as imagens presentes nos mesmos. Durante a observação dos cordéis foi feito a leitura do cordel "Paisagem" (quadro 1) de Leila Freitas de Lucena (20--):

\section{Quadro 1 - Cordel Paisagem}

\begin{tabular}{l}
\hline Recordação do Açude Angico... \\
Espelho que reflete o céu, em dias de \\
Escuridão, em dias de mansidão... \\
Oásis que o vento chacoalha com beijos de amor sem fim \\
A brisa levanta leve, arrepiando cabelos... \\
Pescadores tiram o sustento para as famílias o ano inteiro... \\
Eterno cartão-postal, rodeado por varal com \\
Roupas limpas e cheirosas, batidas em uma \\
Pedra, sem pressa, o dia vai embora...
\end{tabular}

Fonte: Lucena (20--).

Após a leitura, os alunos foram indagados se este cordel realmente falava de paisagem. Muitos afirmaram que sim e, portanto, foram levados a explicar suas respostas. Foi possível observar que as justificativas se relacionavam ao fato de o poema descrever um lugar e suas formas. Porém, quando questionadas em relação à paisagem ser composta apenas por imagem, ou seja, pelo que se vê, os alunos chamaram a atenção para as partes que relatam os sentidos, quando se fala dos odores e dos sentimentos no poema.

Durante o diálogo, foi desenhado no quadro um arranjo de objetos geográficos que configurava uma paisagem que os alunos conheciam da cidade de Londrina. O recorte escolhido foi o do terminal central, englobando o restaurante popular, o museu, o planetário e a super-creche. A partir deste esquema feito no quadro os alunos foram questionados a respeito do que compunha aquela paisagem, se tudo possuía a mesma idade, e se os objetos geográficos estavam distribuídos daquela maneira por mero acaso. Estes 
questionamentos visavam o incentivo a se pensar criticamente as paisagens que fazem parte do entorno dos alunos.

Após a discussão acerca do recorte da cidade de Londrina, os alunos foram divididos em grupos de até quatro pessoas, que escolheram um recorte geográfico de Londrina para que produzissem um cordel referente à paisagem deste local. A orientação foi que escolhessem um lugar conhecido e frequentado pelos mesmos, para que estes pudessem relatar o que estava além do visível, ou seja, era vivido naquela paisagem. Os locais escolhidos foram: Praça Tomi Nakagawa; concha acústica; shopping Boulevard e calçadão de Londrina. Além da poesia, todos os grupos foram orientados a desenharem uma capa para o Cordel.

\section{RESULTADOS E DISCUSSÃO}

Existem diversas concepções errôneas acerca da paisagem que estão presentes no imaginário de professores e alunos. De acordo com Cavalcanti (1998), há a presença de um aspecto estético nas paisagens, sendo este o mais citado entre os alunos pesquisados pela autora. Isto revela a associação do conceito de paisagem com a imagem de lugares bonitos. Além disso, a autora revelou pelas pesquisas a associação do conceito com a natureza, considerando a paisagem como o que é natural. Estas revelações permitem afirmar que o conceito muitas vezes é visto como algo distante da realidade dos alunos, principalmente os inseridos no espaço urbano, no qual as "paisagens naturais" inexistem. Sendo assim, vê-se a necessidade de trazer para o universo do aluno o conceito, permitindo que o mesmo 0 enxergue no lugar que está inserido, contribuindo assim para a compreensão do mundo em que vive.

No final da oficina, um grupo apresentou seu cordel e todos foram recolhidos posteriormente. A partir da leitura dos cordéis foi possível observar que todos partiram inicialmente da descrição da paisagem, levando em conta todas as características que vão além do que é visual. No entanto, os alunos conseguiram atribuir as intencionalidades presentes nestas paisagens, pois refletiam acerca dos aspectos que nem sempre são perceptíveis apenas pelos sentidos, como no cordel a seguir que retrata a Concha Acústica de Londrina (quadro 2).

Neste cordel os alunos descreveram a paisagem escolhida, mas também relataram as relações sociais presentes neste entorno. Além disso, é possível visualizar o apego às percepções ligadas aos sentidos, que retrata os sons e odores. A partir da poesia é possível notar que os alunos não associaram o conceito de paisagem a um local bonito, os mesmos relataram as particularidades e problemas desta paisagem. Por fim, pode ser feita uma 
observação acerca do uso do termo lugar, muito comum no cotidiano das pessoas e presente no poema devido ao vínculo com a paisagem escolhida.

Quadro 2 - Cordel sobre a concha acústica de Londrina

\begin{tabular}{|l|} 
Um lugar cheio de escadas \\
Fuito com um objetivo \\
Um lugar feito pra lazer \\
Mas na realidade da cidade \\
Coisa totalmente diferente se vê \\
Pessoas sem lugar pra ficar \\
Sem família e apoio \\
Na concha resolveram morar \\
Muito barulho se ouve \\
Muita gente se vê \\
A pobreza permanece até morrer.
\end{tabular}

Org.: Patrícia H. M. da Silva.

No cordel "Arodô" (quadro 3) pode-se verificar de forma mais evidente a relação que a paisagem tem com as percepções e sentimentos do indivíduo:

Quadro 3 - Cordel sobre a rodoviária de Londrina

\begin{tabular}{l} 
Paredes que transmitem a amizade \\
Que Ihe permitem a liberdade \\
Ao subir as escadas, lá se vai \\
A saudade pela estrada \\
O que restam às lembranças \\
É manter a esperança \\
\hline
\end{tabular}

Org.: Patrícia H. M. da Silva.

É possível constatar o entendimento do aluno acerca da temporalidade da paisagem pois atribui às formas da paisagem o sentimento de saudade, que está ligado a diferentes tempos vividos. Além disso, a partir da poesia a compreensão da relação que o indivíduo tem com a paisagem é mais nítida, uma vez que para os autores do cordel "Arodô" a rodoviária representa a saudade sentida pelos que partem, enquanto que para outros ela poderia representar a alegria dos que chegam. Neste sentido, a literatura de cordel se mostrou uma ferramenta no auxílio da interpretação das subjetividades presentes nas interpretações dos conceitos. De acordo com o que Moraes e Callai (2012) argumentam, a literatura leva em conta o imaginário de cada um que, conforme sua vivência atribui diferentes significados aos objetos geográficos presentes na paisagem, ultrapassando a mera descrição das formas. 
Pode-se afirmar que a atividade cumpriu seu objetivo, pois ao analisar os cordéis produzidos é possível verificar que todos conseguiram abordar os diversos aspectos da paisagem. Os alunos não mantiveram seu foco apenas na mera descrição, mas, como já citado, conseguiram relatar as relações sociais e as ações existentes em cada recorte escolhido.

Neste sentido, este fato é resultado da apresentação do conteúdo a partir da realidade dos alunos, do seu cotidiano. Ao trazer elementos pertencentes às paisagens que os mesmos vivenciam todos os dias, os alunos puderam perceber que o conceito está além do que é belo e natural. Por fim, alguns alunos escreveram mais que outros, porém todos realizaram a atividade e mostraram sua compreensão acerca do conceito.

\section{CONSIDERAÇÕES FINAIS}

A busca por ferramentas que aproximem os alunos dos conteúdos trabalhados em sala de aula deve ser constante. No caso da Geografia, a possibilidade de se trabalhar de forma interdisciplinar é facilitada pelo próprio histórico desta ciência e pelas diferentes faces do espaço geográfico, estudadas pela mesma. Neste sentido, o emprego dos cordéis como forma de ensino do conceito de paisagem reforçou as inúmeras vantagens de se trabalhar além das fronteiras de uma única disciplina.

Este trabalho interdisciplinar favorece o entendimento da realidade em que o aluno está inserido, pois não fragmenta o cotidiano e o mundo vivido, ao contrário, demonstra que as ações acontecem simultaneamente e que há um ordenamento no espaço e que existem agentes que podem regular o mesmo. É necessário que os conceitos sejam trabalhados de forma contextualizada, não podendo ser soltos e dados como peças que não fazem parte de um todo. A literatura fornece esse contexto e permite que todas as dimensões da paisagem sejam exploradas, além de possibilitar que conexões com outros conceitos sejam feitas.

A literatura também se mostrou uma forma de avaliar o que os alunos realmente entenderam acerca de determinados conteúdos pois, ao permitir que estes criem textos com uma linguagem mais livre a respeito dos assuntos trabalhados, dá-se a possibilidade de se expressar de uma forma menos formal do que em uma prova, por exemplo. A criação de textos e, no caso, de cordéis, foi fundamental para que os alunos estivessem à vontade para usar a própria criatividade e retratarem os conhecimentos acerta das paisagens escolhidas.

Neste sentido, a literatura de cordel possibilitou aos alunos o entendimento, por meio da leitura e da imaginação, dos acontecimentos narrados e das paisagens descritas, levando em conta não apenas os aspectos físicos, mas também os psicológicos das personagens e dos espaços em que estas estão inseridas. Sendo assim, a compreensão do conceito vai além da ideia de este é algo distante e que foge do seu dia a dia. A literatura 
proporciona a aproximação da realidade dos alunos que, ao fazerem seu próprio cordel, se viram na função de observadores e críticos do espaço geográfico em que estão inseridos, favorecendo assim uma reflexão a respeito das diferentes paisagens que os cercam.

Outro aspecto relevante é aproximação dos alunos com literaturas diferenciadas, que fogem das leituras convencionais. Os cordéis representam grande parte da cultura nordestina do país, e proporcionar o contato com tal leitura é permitir que novas culturas sejam experimentadas, favorecendo até mesmo um ambiente para discussões sobre regionalismos e preconceitos existentes no país. Portanto, as contribuições de se trabalhar com a literatura de cordel vão além do entendimento de conceitos da Geografia, envolvem também uma discussão e valorização da cultura do nordeste brasileiro.

A Geografia possibilita ao aluno pensar o espaço geográfico de forma crítica, compreendendo seus arranjos e os porquês de estes serem como são permitindo assim que o aluno aja de forma consciente sobre o meio em que está inserido. Portanto, a literatura de cordel se mostrou como uma aliada no ensino do conceito de paisagem, pois permite que relações com o meio vivido sejam estabelecidas, além de ser uma forma de escrita que dá liberdade para o aluno se expressar e demonstrar como enxerga o espaço geográfico.

Outro aspecto relevante é a forma como o conteúdo foi apresentado. A oficina teve um planejamento voltado para a participação efetiva dos alunos, não se resumindo a uma aula expositiva. Sendo assim, a partir da aplicação da mesma foi possível perceber que o envolvimento dos alunos é mais significativa quando se leva para a sala de aula elementos diferentes dos tradicionais e se permite uma participação mais efetiva dos alunos na construção do conhecimento.

Por fim, esta oficina permitiu a abertura para novas possibilidades quando se trata do ensino de Geografia. A partir da percepção do envolvimento dos alunos e da compreensão sobre o assunto abordado por parte dos mesmos, pode se afirmar que o trabalho com metodologias diversas e a busca da interdisciplinaridade aproximam os conteúdos da vivência dos alunos e auxiliam o professor na busca de aulas mais dinâmicas e diferenciadas.

\section{REFERÊNCIAS}

CARVALHO, M. I. S. S. O que se quis. In: CARVALHO, M. I. S. S. Fim do século: a escola e a geografia. ljuí: Ed. da Uniju, 2007. p. 15 - 50.

CAVALCANTI, L. S. Geografia escolar e a construção de conceitos no ensino. In: Geografia, escola e construção de conhecimentos. Campinas: Papirus, 1998. p. 87 136. 
CORRÊA, R. L. Espaço: um conceito-chave da Geografia. In: CASTRO, I. E.; GOMES, P. C. C.; CORRÊA, R. L. (Org.). Geografia: conceitos e temas. 10. ed. Rio de Janeiro: Bertrand Brasil, 2007. p. 15 - 47.

CURRAN, M. J. A literatura de cordel: antes e agora. Hispania, Madrid, v. 74, n. 3, p. 570 576, Sept. 1991.

FAZENDA, I. C. A. Interdisciplinaridade: qual o sentido? 2. ed. São Paulo: Paulus, 2006. (Questões Fundamentais da Educação, v. 1).

GOMES, P. C. C. Um lugar para a geografia: contra o simples, o banal e o doutrinário. In: MENDONÇA, F.; SAHR, C. L. L.; SILVA, M. (Org.). Espaço e tempo: complexidade e desafios do pensar e do fazer geográfico. Curitiba: Ademadan, 2009. p. 13 - 30.

LUCENA, F. L. F de. Nordeste: o sertão dentro da gente. [S. I.: s. n., 20--]. (Arte e Poesia). MORAES, A. C. R. Geografia, interdisciplinaridade e metodologia. GEOUSP. Espaço e Tempo, São Paulo, v. 18, n. 1, p. 9 - 39, 2014.

MORAES, M. M.; CALLAI, H. C. As possibilidades entre literatura e geografia. In: SEMINÁRIO INTERNACIONAL DE EDUCAÇÃO NO MERCOSUL, 14, 2012, Cruz Alta. Anais... Cruz Alta, 2012. v. 14, p. 1 - 14.

SANTOS, M. Paisagem e espaço. In: SANTOS, M. Metamorfose do espaço habitado: fundamentos teóricos e metodológicos da geografia. 6. ed. São Paulo: UNESP, 2008. p. 67 81.

SUERTEGARAY, D. M. A. Geografia e interdisciplinaridade. Espaço geográfico: interface natureza e sociedade. Geosul, Florianópolis, v. 18, n. 35, p. 43 - 53, jan./jun. 2003.

TEIXEIRA, A. L.; FREDERICO, I. C. Práticas interdisciplinares no ensino de geografia. In: ENCONTRO NACIONAL DE PRÁTICA DE ENSINO EM GEOGRAFIA, 10, 2009, Porto Alegre. Anais... Porto Alegre: UFRGS, 2009. CD-ROM. 